\title{
Graciliano Ramos e Josué de Castro: um debate acerca da fome no Brasil
}

\author{
Ana Paula Kiffer ${ }^{1}$ \\ (Pontifícia Universidade Católica do Rio de Janeiro)
}

\begin{abstract}
RESUMO: ESTE ARTIGO REABRE A QUESTÃO DA FOME NO INTERIOR DAS DISCUSSÕES POLÍTICO-LITERÁRIAS NO BRASIL DE HOJE, A PARTIR DE UMA ANÁLISE QUE CONJUGUE UM ENCONTRO IMAGINÁRIO ENTRE DOIS ESCRITORES ÍCONES DESSE TEMA: JOSUÉ DE CASTRO E GRACILIANO RAMOS. APESAR DAS NATUREZAS DISTINTAS DESSES DOIS DISCURSOS, SENDO UM ORIUNDO DA GEOGRAFIA HUMANA E OUTRO DA LITERATURA FICCIONAL, BUSCAREMOS MOSTRAR COMO AS TESES DO PRIMEIRO ENCONTRAM RAÍZES NA FICÇÃO DO SEGUNDO, E COMO, NUM TERCEIRO MOMENTO, A CRÍTICA LITERÁRIA DE GRACILIANO, CONTEMPORÂNEA DE JOSUÉ DE CASTRO, BUSCOU IMPEDIR O AFLORAR DESSAS MESMAS TESES.
\end{abstract}

ABSTRACT: THIS ARTICLE RE-OPEN THE QUESTION OF HUNGER WITHIN THE POLITICAL-LITERARY DISCUSSIONS IN CONTEMPORARY BRAZIL, BASED ON AN ANALYSIS THAT PROMOTES AN IMAGINARY ENCOUNTER BETWEEN TWO ICONIC WRITERS ON THIS SUBJECT: JOSUÉ DE CASTRO E GRACILIANO RAMOS. IN SPITE OF THINKING ABOUT TWO DIFFERENT KIND OF DISCOURSES, ONE ORIGINATED IN THE HUMAN GEOGRAPHY, AND THE OTHER, IN THE LITERARY FICTION, WE WILL TRY TO SHOW HOW THE FIRST ONE'S THESES FIND THEIR ROOTS ON THE SECOND ONE'S FICTIONAL WORKS, AND, LATER ON, HOW GRACILIANO'S CRITICAL FORTUNE, CONTEMPORARY OF JOSUÉ DE CASTRO, HAS TRIED TO PREVENT THE OUTCROP OF THESE SAME THESES.

PALAVRAS-CHAVE: FOME - MISÉRIA - TABU DA FOME - MEMÓRIA - CRÍTICA. KEY-WORDS: HUNGER - POVERTY - HUNGER TABOO - MEMORY - CRITICISM.

\footnotetext{
1 Professora do Programa de Estudos de Literatura da PUC-Rio. Doutora em Literatura Comparada (UERJ, 2002). Autora de artigos sobre o escritor Graciliano Ramos. Autora do artigo intitulado "Les Corps de la Faim", publicado na Revue Europe (2002), e do livro Antonin Artaud: uma poética do pensamento, publicado em 2003 pela Biblioteca-Arquivo Teatral "Francisco Pillado Mayor" da Universidade da Coruña, España.
} 
riste vida de posseiro junto à Alagoa Amarela.

Vinte anos sobre a terra cavando o faltoso pão, vinte anos de promessa com a mesma enxada na mão, catorze filhos no mundo fora os que estão no caixão.

Peguei na espingarda velha como quem pega o enxadão com a força que a fome dá pra quem defende seu pão" (Cantador Popular)

\section{(I) Caminhos Prévios}

Recentemente um acontecimento de suma importância e visibilidade ocorreu no Brasil: a eleição do presidente Luiz Inácio Lula da Silva e a promulgação do assim chamado "carro-chefe" de seu governo, o programa Fome Zero, lançado formalmente no dia trinta de janeiro de 2003, mas não sem ter sido divulgado anteriormente, durante toda sua campanha eleitoral. De fato, o projeto intitulado Fome Zero - Uma Proposta de Política de Segurança Alimentar no Brasil foi lançado em outubro de 2001, pelo Instituto de Cidadania, órgão não-governamental criado por Luiz Inácio Lula da Silva entre outros. O Projeto foi resultado de um ano de trabalho junto às organizações não-governamentais, institutos de pesquisa, sindicatos, organizações populares, movimentos sociais e especialistas. Já nesse projeto, de domínio público, ${ }^{2}$ contava-se atender quarenta e quatro milhões de pessoas no interior de um quadro de oitocentos e vinte e seis milhões de famintos em todo o mundo. Quarenta e quatro milhões de pessoas que se encontram hoje no Brasil abaixo da linha de pobreza recebendo cerca de oitenta reais por mês. O projeto Fome Zero

2 Ver em www.pt.com.br 
vem, desse modo, recuperar compromissos interrompidos com a sociedade brasileira desde a década de sessenta, e não sem polêmica se confrontar com as soluções extremas da questão, que vão do assistencialismo ou medidas emergenciais às políticas de distribuição de renda, o que significaria tocar nos grandes nichos de riqueza que sustentam o mercado da fome no Brasil e no mundo. Nas palavras do próprio Presidente o projeto prevê “dar peixe e ao mesmo tempo ensinar a pescar". ${ }^{3}$

Ora, a emergência de um debate e de uma mobilização nacional em torno da fome, claro, não poderia deixar de colocar alguns problemas ao desejo inicial desse trabalho. ${ }^{4}$ Mas que problemas efetivamente essa confluência coloca? Em primeiro lugar, a preocupação imediata de que uma reflexão que vem ainda desejando se desdobrar se encontre capturada pelas inevitáveis teias ideológicas do discurso muitas vezes inerentes às manifestações críticas sobre as questões da ordem do dia, do imediato contemporâneo. Ainda mais além está o próprio delicado sujeito da fome, que em si traz inúmeras questões que atravessam o campo da reflexão impelindo-a para a ação. Desse modo, tais preocupações tornaram-se o solo inicial da reflexão que se quer desenvolver. Dito de outro modo: a inevitabilidade do discurso ideológico será tratada aqui como uma hipótese constante nas análises dos textos e autores que se irá trabalhar e, ainda, como dificuldade ou problema intrínseco à atividade crítica diante do sujeito em questão. Esboçar esse caminho prévio tornou-se inevitável para abordar hoje a questão da fome no Brasil. Mesmo que o percurso que se pretenda aqui não seja o de pensar a fome hoje no Brasil, tampouco o Programa que começou a se realizar no interior desse governo. Não se trata, portanto, de um trabalho sobre o Fome Zero, trata-se de reencontrar essa mesma questão da fome, em formações discursivas distintas e situadas noutro momento histórico, para quiçá, a partir daí, poder cruzar os discursos e encontrar parte do solo que hoje quer reaflorar nas terras do Brasil.

O recorte aqui escolhido obedece menos a uma escala temporal (o que não significa dizer que a historicidade dos discursos esteja ausente) e mais às

3 Discurso Oficial de lançamento do programa Fome Zero, pronunciado no dia trinta de janeiro de 2003 no Palácio do Planalto.

4 Este trabalho fez parte de uma pesquisa intitulada "Escrita e Corpo: por um pensamento do corpo e uma literatura da fome" financiada pelo CNPq na modalidade de Bolsa Recém-Doutor na PUC-RJ/ Depto. de Letras. 
diferenças de formações discursivas que, no entanto, estariam se confrontando com o mesmo problema da fome. Temporalmente os discursos que serão abordados começam a falar no fim da Segunda Grande Guerra e alcançam, no Brasil, a década de sessenta com suas amplas aspirações revolucionárias. É importante assinalar ainda, o fato de que este trabalho se constrói em torno de dois momentos distintos: (1) no primeiro, há um esforço de conceituação da questão, esforço afirmativo onde se pretende positivar a fome ou, dito de outro modo, momento em que se busca construir e operar com uma determinada categoria da fome; (2) o segundo momento dedica-se à necessidade de apontar os compromissos ideológicos que se colocam face ao problema da fome e, nesse sentido, propõe-se a tarefa de desconstruir tais discursos, ou seja, incidir sobre o campo de uma crítica negativa preocupada, porém, em afirmar outros caminhos para se pensar e desdobrar a questão.

\section{(II) O Tabu da Fome}

Não me parece que seja necessário discutir aqui a obviedade do impacto causado pelos destroços das guerras e a necessidade de reconstrução de um projeto de humanidade que necessariamente conjugam discursos acerca da fome no mundo, a partir, sobretudo, da Segunda Guerra Mundial. No entanto, o que não me parece tão óbvio seriam as relações entre a guerra e a fome, que em muito ultrapassam a evidência dos grandes quadros de miséria causados pela guerra. Isso porque a fome vem sendo muito mais do que um simples efeito, o próprio instrumento ou uma das armas utilizadas nos estados de guerra. ${ }^{5}$ Nesse sentido, se deseja levantar hipótese central na qual a fome se apresente positiva e afirmativamente capaz de operar contra a miséria provocada pelos estados de guerra. Trata-se de encontrar aí, na aliança com outras vozes, a força da fome quando esta é tomada seja por um indivíduo ou, mais ainda, pelas coletividades. Força que é a única capaz de diferençá-la do quadro de miséria orquestrado e produzido pelo homem. Tomar para si a sua própria fome significa situá-la fora dos fatalismos dos discursos que pretendem ainda hoje localizá-la na ordem dos fenômenos naturais, ou como simples efeito

5 Basta sublinhar aqui o bloqueio norte-americano a Cuba. 
das catástrofes humanas, dentre elas a própria guerra. Assim, a fome se diferenciará da miséria e poderá operar no combate contra a mesma.

No Brasil ninguém melhor e mais profundamente do que Josué de Castro colocou, pesquisou e combateu os discursos que pretendem manter a miséria afastando os homens de sua própria fome. Tais discursos atribuem à fome a fatalidade da natureza, defendendo ser a superpopulação sua causa no mundo e situando-a, desse modo, como acidente geográfico relacionado à falta de produção de alimentos. Nota-se que tais teses só foram ultrapassadas recentemente no debate internacional, como se pode observar no interior do próprio projeto Fome Zero - Uma Proposta de Política de Segurança Alimentar no Brasil, realizado em 2001.

Em 1946 Josué de Castro escreveu a primeira versão de seu livro, traduzido em mais de vinte e cinco idiomas, A geografia da fome, o dilema brasileiro: pão ou aço. Livro este que para toda uma geração, formada nos anos cinqüenta e sessenta no Brasil, veio a ser um clássico e mais do que isso, um artefato capaz de gerar ações além de reflexões. Por conta dos quase vinte anos de ditadura militar, o livro caiu no esquecimento e só agora, em 2001, foi reeditado pela Fiocruz. Luiz Inácio Lula da Silva terminou seu discurso de lançamento oficial do programa Fome Zero em Brasília homenageando o autor da Geografia da fome, seu conterrâneo, que veio a ser o presidente do conselho de Organização para Alimentação e Agricultura das Nações Unidas (FAO). Josué foi, e ainda é, pioneiro por levantar um tema que ele mesmo nomeou como sendo "o tabu da fome". Num livro posterior, esse já de 1966, Geopolítica da Fome, o autor interroga:

Será a calamidade da fome um fenômeno natural inerente à própria vida, uma contingência irremovível como a morte? Ou será a fome uma praga social criada pelo próprio homem? Eis o delicado e perigoso assunto debatido nesse livro. [...] tão delicado e perigoso por suas implicações políticas e sociais que até quase os nossos dias permaneceu como um dos tabus da nossa civilização - uma espécie de tema proibido ou pouco aconselhável para ser abordado publicamente.(CASTRO, 1965: 45)

Em seu primeiro livro, A geografia da fome, de 1946, Josué se dedicou a analisar o fenômeno da fome e desnutrição em cada região do Brasil. Este livro se enuncia como um grande estudo de segurança alimentar, onde se 
descobre, no interior de uma narrativa detalhada sobre os costumes alimentares e culturais de cada região teses ainda hoje revolucionárias. Levantemos aqui tese de suma importância para o sujeito em questão: o autor nos mostra um quadro de fome endêmica no nordeste litorâneo do Brasil e não no semi-árido do sertão, onde aí a fome se manifesta de modo epidêmico. Ora, a endemia da fome numa região de extrema riqueza natural só se justifica através das grandes fazendas de monocultivo, sobretudo de cana-de-açúcar, que, como sabemos, concentram historicamente no Brasil um imenso poder sociopolítico e econômico. Nesse mesmo livro, escrito há mais de 50 anos Josué de Castro já afirmava: "Trata-se de um silêncio premeditado pela própria alma da cultura. Foram os interesses e os preconceitos de ordem moral e de ordem política e econômica [...] que tornaram a fome um tema proibido." (CASTRO, 2001: 12)

Antes de desdobrar aqui as hipóteses centrais defendidas por Josué de Castro deve-se explicitar os diálogos que com as suas hipóteses se vai travar. Para tanto, vale lembrar que a literatura no Brasil já da década de trinta (e mesmo muito antes) explorava e se confrontava com a fome. Os chamados "romances nordestinos" de Rachel de Queiroz, Zé Lins do Rego e Graciliano Ramos, para citar apenas alguns expoentes, vinham na longa trajetória das secas no Nordeste abordando "tão delicado e proibido tema". Josué de Castro, por sua vez, não deixa de citar, lembrar e mesmo se inspirar em alguns desses autores. Seria, portanto, na interseção de seu discurso crítico e do discurso literário que estaria buscando pensar a fome. Tomando como caso e objeto privilegiado para essa interseção o romance Vidas secas, escrito em 1938 por Graciliano Ramos. Ainda como objeto último desse trabalho se deve confrontar a crítica de Josué de Castro com a crítica literária que recebeu e legitimou Graciliano Ramos. São textos contemporâneos ao da Geografia da fome, mas, que, não sem surpresas, nos colocarão diante de um quadro deveras distinto deste.

Para o autor da Geografia e da Geopolitica da fome, o "tabu da fome" erige duas hipóteses centrais que irão atravessar todas as suas reflexões. A primeira delas é de ordem moral: o pensamento moderno ocidental calcado na razão vai necessariamente ter de excluir tudo aquilo que é da ordem "instintiva" e afetiva. Poder-se-ia dizer que aquilo que não cabe na razão é o corpo, e nesse caso o corpo da fome. Para Josué, atento leitor de Freud, a fome é aliada ao sexo e 
enquanto "instintos" devem ser recalcados. Daí a hipótese moral que norteia seu trabalho, hipótese que vai nos atribuir a vergonha de nossa própria fome. É importante lembrar que o discurso de Josué de Castro não se insere numa pesquisa sobre as subjetividades, ou sobre as sensações da fome no indivíduo, ${ }^{7}$ seu assunto é a coletividade calcada em análises situadas no quadro de uma geografia humana ou, ainda, no quadro das sociologias políticas. No entanto, e talvez por isso mesmo, seu discurso se torne ainda mais subversivo, posto que nenhuma armadura científica ou disciplinar é capaz de deter a fome desse pesquisador em colocar o dedo nas feridas dos homens modernos e de seus sistemas de pensamento aparentemente bem assentados. Ora, a vergonha de nossa própria fome viria vinte anos depois da Geografia se manifestar no contundente libelo do Cinema Novo, a Estética da fome assim escrita por Glauber Rocha:

Desse modo nós definimos nossa cultura como uma cultura da fome. Nós compreendemos esta fome que o Europeu e o Brasileiro, em sua maioria, não compreendem. Para o Europeu é um estranho surrealismo tropical. Para o Brasileiro é uma vergonha nacional. Ele não come, mas ele tem vergonha de dizer e, sobretudo, ele não sabe de onde vem essa fome. (ESTÈVE, 1972)

Glauber busca uma resposta ético-estética ao problema apontado por Josué. Como deflagrar essa vergonha? Como dar a ver esses territórios esquecidos sem cair no paternalismo, no folclore, na linhagem de espetacularizar a nossa própria miséria? Ora, Glauber vem confirmar a hipótese de Josué segundo a qual a vergonha tem amarras em lugares mais longínquos do que aqueles baseados nos ditames da boa educação e do bom comportamento. A vergonha, em Glauber Rocha e em Josué de Castro, está profundamente associada à impossi-

6 A leitura de Josué de Castro da obra de Sigmund Freud está inevitavelmente marcada pela tradução e pela tradição inglesa e americana, donde se infere a palavra "instinto", tradução deveras discutível para o conceito "trieb" em alemão. Hoje tal conceito é largamente traduzido pela palavra em português "pulsão". Sendo a pulsão um conceito limite na obra freudiana entre o psíquico e o somático. Não podendo, por conseguinte, ser atribuída simplesmente à idéia de uma "natureza" humana, seja ela biológico-evolutiva ou genética. O conceito de pulsão aponta, portanto, para um corpo-psíquico construído culturalmente. Ele é um conceito de borda, que norteia tanto a prática clínica da psicanálise quanto a possibilidade de constituição do psiquismo fora do âmbito psicológico, remetendo o sujeito para as relações históricas e materiais concretas, cuja matriz inicial é o próprio corpo do indivíduo.

7 Sobre esse assunto ver, por exemplo, estudo de Paul Auster (1995). 
bilidade de se reconhecer como tal. A hipótese moral não se relacionaria com a boa educação, mas talvez com a legitimidade, oriunda da compreensão de onde vem a sua própria fome. De outro modo, seguimos calados, dóceis e envergonhados. A vergonha aqui é aliada do silêncio, da impossibilidade de dizer, e, portanto, essa fome é também fome de palavra, é ausência da mesma.

Uma segunda hipótese vem somar-se a esta nas análises da Geografia e da Geopolítica da fome. Trata-se, como disse o autor, de "[...] razões cujas raízes mergulhavam no escuso mundo dos interesses econômicos, dos interesses das minorias dominantes e privilegiadas, que sempre trabalharam para escamotear o exame do fenômeno da fome do panorama intelectual moderno" (CASTRO, 1965: 49). Ora, mesmo que hoje essa assertiva soe já bastante conhecida - passadas as inúmeras discussões sobre o colonialismo devastador, nas palavras do próprio Josué, e até mesmo chegando às discussões sobre os pós-colonialismos - ao menos, no Brasil, nós ainda não sabemos o que significa tocar no quadro da distribuição de riquezas ou nos velhos esquemas de privilégios das minorias dominantes. Lugar, portanto, ainda fundador para qualquer confronto com a questão da fome nesse país.

Interessaria assinalar que essas duas hipóteses centrais para as análises do autor estariam operando com um só e mesmo conceito: o conceito de recalque. Seja ele de ordem moral ou econômico-político-social trata-se, em ambos os casos, de recalcar escamotear, proibir, impedir. Não se quer aqui negar a existência dessa hipótese repressiva; no entanto, deseja-se contribuir com a mesma, pelo simples fato de que se Josué leu e citou Freud, nós hoje já devemos ter lido Freud, mas também Foucault. ${ }^{8}$ Isso significa que à hipótese repressiva vem somar-se a hipótese produtiva. Bastante apropriado se não deixamos de assinalar a preocupação inicial com este trabalho, donde se infere um momento que deseja produzir discursos sobre a fome no Brasil. A repressão continua, dado que as estruturas não se transformaram, no entanto, se intenta produzir uma mobilização nacional em torno da fome que, inevitavelmente, traz em si mesmo o risco de uma produção discursiva que abrande, quando não, que banalize as forças e as potências que circundam certa categoria de fome. Seis de fevereiro de 2003, o Jornal do Brasil anuncia: "Emergente doa o colar da sua cadelinha para o Fome Zero". A foto, na primeira página, mostra a Sra. Vera Loyola

8 Sobre a hipótese produtiva em contraposição à hipótese repressiva ver, sobretudo, Foucault (1976; 1984). 
beijando na boca de seu cão de estimação. A matéria descreve: “[...] a jóia de dezoito quilates com pingente de ouro cravejado de brilhantes, está avaliada em $\mathrm{R} \$ 3$ mil e oitocentos reais de acordo com a socialite. O colar havia sido dado de presente à cadela pelo padrinho do bicho o joalheiro Bernardo Langlotti." (eu grifo).

\section{(III) Secas, as vozes da fome?}

Observemos agora os objetos privilegiados dessa discussão: as teses de Josué de Castro diante do romance Vidas secas de Graciliano Ramos e de sua crítica literária, nesse momento anterior de debate sobre a fome no Brasil. Vidas secas toca, com precisão, num dos eixos que estruturam, e ainda hoje estruturam, a sociedade brasileira. Nesse eixo continuam presentes elementos já abordados em dois livros anteriores do mesmo autor, Caetés e São Bernardo. Do primeiro resta o esquecimento - o não conhecimento de nossa própria história - isso que era evocado através dos índios caetés e, com ele, todo um passado engolido e triturado pelos colonizadores. ${ }^{9}$ Do segundo, São Bernardo, resta a miséria humana que se articula em torno da riqueza de poucos e a pobreza de muitos. Em $V$ idas secas, Graciliano vem narrar esse mundo periférico que é o Sertão e seu povo. Dar voz ao esquecimento. E em meio ao silêncio a narrativa se constrói. O silêncio é o esquecimento e a própria voz dos personagens, já que esses são quase mudos, com poucos diálogos e frases grunhidas que, em sua maioria, são contadas por um narrador em terceira pessoa. Os capítulos evocam o silêncio na voz singular de cada personagem. Os personagens não se restringem ao ser humano - posto que se trata de abordar o desumano como parte integrante de nossa realidade. Vidas secas é narrativa em espiral onde o cíclico próprio à seca

9 Não por acaso Graciliano parece operar aqui com uma visão crítica, diria mesmo invertida, da lição produtiva da antropofagia oswaldiana. A devoração aqui implica sempre no risco de total submissão do outro, apagamento do lastro histórico, impossibilidade de reconstrução de um passado sem pistas, verdadeiramente “comido" pelo colonizador. Nesse sentido, Graciliano aponta para a própria voracidade do discurso histórico oficial, do desejo impetuoso do colonizador, invertendo o traço antropofágico para fora dos limites nacionais e mostrando sua sombria feição. Indico aqui a leitura de Benjamin Abdala Jr., no artigo intitulado "Graciliano Ramos e a Totalidade Imaginada", publicado nos Cadernos da Católica (Brasília, Universidade Católica de Brasília, 1996). Neste texto o autor sublinha o conflitante traço antropofágico presente em Caetés. Gostaria, no entanto, apesar de não ser esse o enfoque deste trabalho, de indicar que a questão da devoração do outro reaparece de modo latente ou manifesto em todos os romances de G. Ramos. 
já se apresenta no primeiro capítulo intitulado "Mudança" - nele lemos, através de um narrador em terceira pessoa, a história de uma família que se retira de uma terra em busca de outra onde possa sobreviver. Esse mesmo movimento cíclico é deslocado no último capítulo - onde da "Mudança" primeira passamos à "Fuga" do final. Há a repetição, já que se trata de ciclo e, de novo, retirada. Mas o que se expressa de diferente entre a mudança e a fuga? A densidade de uma vida seca, o inefável "mundo coberto de penas", ${ }^{10}$ aquilo que não se conseguiu mudar e que, mais forte do que nós, nos leva à fuga?

Do romance Vidas secas será evocado um episódio cuja força imagética e a diversidade de significados incidem precisamente sobre a questão da fome. Desse modo, tal cena será tratada como um dos núcleos dessa narrativa. $\mathrm{O}$ episódio é trágico e narra o momento em que o Papagaio (membro da família) é comido pela própria família. ${ }^{11}$ Coloca-se a seguinte questão: a cachorra Baleia come os restos do Louro, mas, segundo o narrador, não guarda lembrança disto. E é somente nesse momento em que algo da memória diferencia Fabiano, Sinhá Vitória e as crianças de Baleia e o Papagaio. Partimos, portanto, do fato de que todos são bichos, semelhantes corpos da fome. $\mathrm{O}$ humano não se caracteriza mais naquilo que nos é dado reconhecer, como por exemplo, a razão, a fala ou a inteligência. Mas é só nesse percurso que chegamos a um traço de diferenciação: esse traço, em Graciliano Ramos, é a memória e sua íntima relação com a morte, ou com a consciência da finitude, com os traços que portam o corpo. Baleia tem angústia, fome, medo, mas desconhece a morte do amigo e, por conseguinte, desconhece a sua própria morte. Parece importante observar que se trata mais de recolocar a questão sobre o humano, através do confronto com esses corpos da fome. A possibilidade de pensar o homem e sua relação com o mundo oferecido por Graciliano, se distancia radicalmente de um sentimentalismo ou de uma psicologia desse mesmo homem-mundo. E seria a partir daqui que se deveria discutir

10 Este teria sido um dos títulos cogitados por Graciliano para o romance Vidas secas.

11 Mais uma vez deve-se sublinhar, em torno ao episódio citado, a reaparição do conflito antropofágico, que em Graciliano se faz sempre como impossibilidade de devorar o outro, o que deve ser entendido em termos de construção da escrita literária como conflito diante da própria (im)possibilidade de representar o outro. Há algo que vem sempre desautorizar o lugar autoral em sua ficção. Mais tarde tudo isso se fará libelo nas mais de seiscentas páginas de um "testemunhar" problematizado pelo autor nas suas Memórias do cárcere. 
com a crítica que recebeu e legitimou Graciliano Ramos como um clássico da literatura brasileira. Ressalta-se, para tanto, a questão da fome, que nesse caso está intimamente relacionada à cultura da fuga, a visão crua e cruel da seca, condensada na imagem aqui evocada. Não se pretende esgotar nenhum entendimento sobre Vidas secas, até porque esse pequeno grande livro continua desafiando as nossas experiências estéticas e políticas no Brasil. Apenas se deseja indicar pontos de tensão entre certa crítica literária face às questões postas nos romances de Graciliano, assim como essas que vimos considerando até então e que fizeram da fome, nesse momento no Brasil, um traço a não poder mais ser negado ou impedido.

Tais textos críticos começaram a ser escritos na década de quarenta e são contemporâneos tanto de Graciliano Ramos quanto de Josué de Castro. Esses mesmos textos foram por muitos anos os prefácios e posfácios que acompanharam a publicação de Graciliano - autor que integra o currículo de todas as escolas no Brasil. Logo, foi através desse olhar que aqui discutiremos que o autor foi inserido em muitos dos carentes quadros da educação fundamental da sociedade brasileira. Vale assinalar que esse reconhecimento por parte da crítica esteve fundado num discurso que pretendia dizer a verdade da obra e até mesmo do escritor. Essa autorização à verdade que funda os discursos que veremos aqui, não deixa de indicar - mesmo à sua revelia - qual seu problema fundamental. Ele se situa num pensamento a priori e que, no tocante à obra de Graciliano Ramos, envolve as noções de indivíduo e sociedade, memória e ficção, psicológico e político. E as envolve em torno de um pensamento marcadamente dualista. Logo, trata-se de como o crítico compreende tais noções e de que forma elas são articuladas. Num certo sentido, trata-se de estar atento a que servem esses discursos na reivindicação de uma literatura e de uma crítica brasileiras. Resumindo: Quais são as verdades de que pretendem nos convencer tais críticos? A que servem essas verdades no universo literário e crítico da sociedade brasileira?

Wilson Martins escreve um posfácio a Caetés intitulado "Graciliano Ramos, o Cristo e o Grande Inquisidor”. Ele escreve:

Embora na tarefa de interpretação literária eu empreste medíocre importância às convicções políticas, religiosas ou sociais dos autores, não posso fugir à necessidade de acentuar a contradição que existe entre essa invariável tendência psicológica de Graciliano Ramos [...] e as idéias políticas que defende, [...]. (eu grifo). 
Ressalto: a contradição entre o que o crítico chama de tendência psicológica e idéias políticas defendidas pelo autor. Importa, agora, a idéia de contradição. Ela serve como exclusão do campo político e como valorização que consolida Graciliano Ramos como um investigador da alma humana. Ele continua:

É um romance psicológico no mais amplo sentido da palavra. [...] Graciliano Ramos não é um fanático do grupo, nem tem pretensões a documentador da vida social. [...] É antes o problema do Bem e do Mal o que atormenta o escritor alagoano, e dito isto terei definido toda a sua obra. [...] Seu olhar, assim, se dirige para mais longe do que o imediato dos homens formigando e defendendo as suas reivindicações de classe. A fonte do problema é uma fonte mais profunda e mais longínqua [...]. Na origem de todas as perturbações Graciliano Ramos não encontrou um desajustamento econômico nem uma injustiça social, mas uma confusão moral. (eu grifo).

O psicológico serve, de um lado, à sufocação das questões sociais, e de outro, à consolidação de um Brasil longínquo: “olhe, nós escrevemos literatura universal, não somos primitivos nem atrasados, tratamos do Bem e do Mal". Wilson Martins também não deixou de falar sobre Vidas secas:

E de que isso é verdade (o problema moral e ontológico), temos a confirmação quase material, uma espécie de índice decisivo, no último romance de Graciliano Ramos, Vidas secas. É o drama das secas mais uma vez no romance. Seria um fenômeno meteorológico condicionando a vida dos personagens, a sua psicologia e seus atos. [...] Mas o que há é o estudo psicológico de Fabiano, o de Sinhá Vitória, o dos meninos, o de Baleia, o do soldado amarelo. (eu grifo).

Aqui somos levados a crer que a seca no Brasil se esgota como um fenômeno puramente meteorológico - confirmando as teses acusadas por Josué de Castro no tocante ao "tabu da fome" - e que Graciliano o desconsidera para triunfar como o primeiro psicólogo brasileiro de família e de animais. Esse pensamento antagonista e dualista vai se desenvolver em torno do escritor e pretende convencer de que a ficção - participando das invenções - fica do lado da mentira. Tal crítica nega à literatura o estatuto de pensamento e, por conseguinte, de participante das formações discursivas na sociedade. Curiosa negação, já que, como vimos, para um cientista como Josué de Castro os romances da seca em muito influíram na sua visão sobre o problema. 
Adonias Filho, crítico que acompanhou a produção de Graciliano, escreve em fim dos anos 40, texto que é posfácio a Insônia, intitulado "Volta a Graciliano Ramos", no qual escreve:

A preocupação estilística e a sondagem psicológica [...] não bastaram para ocultar a tendência visivel, o interesse regional, o acentuado ruralismo. [...] A estrutura social subsiste em função do acontecimento bumano, em todos dependendo das contingências (guerra, revolução, seca) [...]. A primeira conclusão pois, é a de que a representação social resulta do núcleo bumano [...] Graciliano Ramos não subordina apenas o cenário ao homem, mas no homem penetra em busca dos grandes problemas. [...] (eu grifo).

Destaca-se: o acentuado ruralismo. Esse dado novo é de suma importância para se compreender a cultura brasileira. Efetivamente não nos interessa esse Nordeste. E com ele a pobreza que é claramente aludida como contingência. Passamos da meteorologia ao histórico e social como contingente. O social é visto como periférico, como universo pitoresco, regional. Graciliano só continuaria a resistir, apesar de seu "acentuado ruralismo", pelo fato de que esse escritor faz subsistir o social em função do universal humano. A mesma contradição é derivada aqui para um entrosamento perfeito, e perfeito porque hierárquico. Porque seu ruralismo estaria subjugado ao conhecimento que esse escritor tem das línguas. Tradutor de Albert Camus no Brasil, Graciliano, apesar de periférico, é possuidor da cultura clássica que marcaria então toda sua escrita.

Para finalizar, assinalemos ainda alguns pontos que consolidam o projeto crítico em torno de Ramos até fins de 50 no Brasil. ${ }^{12}$ Dele extraímos: 1) A vida real confunde-se com a memória, a memória - gênero narrativo - passa a explicar a ficção - outro gênero narrativo. 2) A memória é entendida como patrimônio, como edificação do passado vivido. 3) No que concerne a escrita esse patrimônio da memória é psicológico, edificação do eu do autor. 4) Assim entendida, a memória pode gerar uma crítica explicativa, prenhe de julgamento, possuidora da verdade sobre o outro. Tal memória se restringe ao universo do eu autobiográfico - história da personalidade - e assim ela é incompreendida como traço da escrita de Graciliano, como processo constitutivo do criar,

12 Efetivamente será a crítica de Antonio Candido que finalmente irá retirar a estufa de silêncio premeditado que se abateu sobre a obra de Graciliano Ramos. 
construir. 5) Efetivamente a crítica literária nesse momento no Brasil não quis se confrontar com o velho problema entre a pesquisa da obra e os efeitos do discurso na sociedade, entre a neutralidade e o engajamento. Essa crítica se engajou cegamente. Um engajamento que denota como o "tabu da fome" levantado por Josué de Castro encontra raízes sólidas. 6) Ainda hoje conceitos como regionalismo continuam operando no interior do universo literário merecendo poucas críticas e reflexões sobre os tentáculos que ele engendra. 7) Hoje tudo isso já está mais diluído, mas, de perto, não deixa de abafar a longa história que Josué de Castro e tantos outros romancistas brasileiros levantaram há mais de 50 anos como parte de um todo que ainda é o Brasil.

\section{Referências Bibliográficas}

ABDALA JR. Graciliano Ramos e a totalidade imaginada. In: Cadernos da Católica. Brasília: Universidade Católica de Brasília, 1996.

AUSTER, Paul. Le Carnet ronge. L'Art de la faim. Essais. Traduit de l'americain par Christine Le Boeuf. Quetigny-Dijon: Babel, Actes Sud, 1995.

CASTRO, Josué de. Geopolítica da fome: ensaio sobre os problemas de alimentação e de população, v. I. São Paulo: Brasiliense, 1965.

. Homens e caranguejos. Rio de Janeiro: Civilização Brasileira, 2001.

- Geografia da fome. O dilema brasileiro: pão ou aço. Rio de Janeiro: Civilização Brasileira, 2001.

ESTÈVE, Michel (Org.). Études Cinématographiques: le "cinema nôvo" brésilien. Paris: Lettres Modernes, Minard, 1972.

FILHO, Adonias. Volta a Graciliano Ramos (Posfácio). In: RAMOS, Graciliano. Insônia. Rio de Janeiro; São Paulo: Record, 1982 [1947].

FOUCAULT, Michel. Histoire de la sexualité. Paris: Gallimard, 1976 (v. I), 1984 (v. II e III).

KAFKA, Franz. Um artista da fome e $A$ construção, tradução do alemão e posfácio de Modesto Carone. São Paulo: Brasiliense, 1994 [1984].

LINS, Álvaro. Valores e misérias das vidas secas (Posfácio). In: RAMOS, Graciliano. Vidas Secas. Rio de Janeiro; São Paulo: Record, 1993 [1938].

MARTINS, Wilson. Graciliano Ramos, o Cristo e o Grande Inquisidor (Pósfacio). In: RAMOS, Graciliano. Caetés. Rio de Janeiro; São Paulo: Record, s.d.

QUEIROZ, Rachel de. O Quinze. São Paulo: Siciliano, 2001 [1930]. 